\title{
Correlation between EGFR mutation status and response to first-line platinum-based chemotherapy in patients with advanced non-small cell lung cancer
}

\author{
This article was published in the following Dove Press journal: \\ OncoTargets and Therapy \\ I July 2014 \\ Number of times this article has been viewed
}

Shu Fang'
Zhehai Wang
Jun Guo'
Jie Liu²
Changzheng Li'
Lin Liu'
Huan Shi'
Liyan Liu'
Huihui Li
Chao Xie
Xia Zhang
Wenwen Sun
Minmin Li'
'School of Medicine and Life Sciences,
University of Jinan-Shandong Academy
of Medical Sciences, ${ }^{2}$ Department of
Oncology, Shandong Cancer Hospital,
Jinan, Shandong Province, People's
Republic of China

Correspondence: Zhehai Wang Department of Oncology, Shandong Cancer Hospital, 440 Jiyan Road, Jinan, Shandong 250I 17, People's Republic of China

Tel $+865316762633 \mid$

Fax +86 53| 6762 633 I

Email wzhai8778@sina.com
Background: The purpose of this research was to investigate the relationship between epidermal growth factor receptor $(E G F R)$ mutations and the response to first-line chemotherapy in patients with advanced non-small cell lung cancer (NSCLC).

Methods: A total of 266 patients with stage IIIB or IV NSCLC who received platinum-based doublet therapies as first-line chemotherapy were investigated retrospectively, and their clinical data were assessed according to EGFR mutation.

Results: $E G F R$ mutations were identified in $45.5 \%$ of patients. There was no significant difference in response rate between $E G F R$ mutation carriers and $E G F R$ wild-type carriers $(P=0.484)$. Among the patients with Kirsten rat sarcoma viral oncogene homolog $(K R A S)$ wild-type, however, those with EGFR mutations responded better to treatment than EGFR wild-type patients $(46.2 \%$ versus $20.8 \%, P=0.043)$. The disease control rate associated with pemetrexed-based treatments was higher than for vinorelbine-based therapies in EGFR mutation patients $(P=0.001)$. EGFR mutation was found in patients with longer progression-free survival and median survival time, and improved 1-year and 2-year overall survival when compared with $E G F R$ wild-type patients (6.1 versus 5.0 months, $P=0.004 ; 18.9$ versus 13.8 months, $P=0.001 ; 81.0 \%$ versus $63.4 \%$, $P=0.002$; and $33.9 \%$ versus $22.8 \% P=0.044$, respectively). Patients with the $E G F R$ exon 19 mutation had longer progression-free survival than those with $E G F R$ exon 21 mutation $(P=0.007)$. Multivariate analysis showed that the response to first-line chemotherapy and the presence of $E G F R$ mutations were independent prognostic factors in patients with advanced NSCLC.

Conclusion: Our data showed that the presence of EGFR mutations meant longer survival times for patients with advanced NSCLC who received platinum-based doublet first-line chemotherapy, especially in those with the exon 19 deletion mutation. Among KRAS wild-type patients, those with EGFR mutation responded better to first-line chemotherapy than EGFR wild-type patients.

Keywords: non-small cell lung cancer, chemotherapeutic agents, epidermal growth factor receptor mutation, targeted therapy, prognosis

\section{Introduction}

Lung cancer continues to be the main cause of carcinoma-related death throughout the world, ${ }^{1}$ and $75 \%-80 \%$ of these cancers are non-small cell lung cancer (NSCLC). ${ }^{2}$ Although surgery is the most effective treatment for NSCLC, about $70 \%$ of patients with NSCLC miss the opportunity for surgical resection because of their advanced disease at presentation. ${ }^{3}$ Chemotherapy is the preferred treatment for these patients. 
There has been research showing that NSCLC patients with the epidermal growth factor receptor (EGFR) mutation respond better to EGFR tyrosine kinase inhibitors (TKIs) in terms of long-term survival. ${ }^{4}$ Several Phase III clinical trials also indicated that NSCLC patients with mutated EGFR had better clinical outcomes from treatment with erlotinib or gefitinib than from normal chemotherapy. ${ }^{5-7}$ At present, EGFR is the primary predictor of a curative effect of EGFR TKIs, and the relevant research ${ }^{8-10}$ has shown that the mutation status of $E G F R$ is probably the main determinant of response to first-line chemotherapy and the prognosis in patients with advanced NSCLC.

The standard first-line regimen for advanced NSCLC is platinum-based doublet chemotherapy. ${ }^{11,12}$ Common chemotherapeutic agents are gemcitabine, docetaxel, vinorelbine, and pemetrexed, but there continues to be a lack of predictive biomarkers to select drugs for first-line chemotherapy. On this background, we reviewed the clinical outcomes in patients with advanced NSCLC who received platinum-based doublet therapies as first-line chemotherapy, and analyzed the predictive value of EGFR mutation status with regard to short-term effects and long-term survival in order to optimize the treatment of individual patients with advanced NSCLC.

\section{Patients and methods}

\section{Patients}

A total of 665 cases of stage IIIB or IV NSCLC treated at Shandong Tumor Hospital from July 2008 to December 2011 were screened, and 266 who received platinum-based doublet chemotherapy as their first-line treatment were analyzed retrospectively. These patients satisfied the following selection criteria: having a pathological diagnosis of NSCLC, clear EGFR mutation status, platinum-based doublet first-line chemotherapy for at least two cycles, measurable lesions, no uncontrolled diabetes or other serious disease, and an Eastern Cooperative Oncology Group performance status of $0-1 .{ }^{13}$

\section{EGFR mutation analysis}

Sequence analysis of EGFR exons 18-21 was done by pyrosequencing, as described elsewhere. ${ }^{14}$ Briefly, the presence of tumor cells was identified on sections stained with hematoxylin and eosin. Formalin-fixed paraffin-embedded tissue samples were microdissected to confirm that the samples contained not less than $80 \%$ tumor cells. Xylene and ethanol were used to remove paraffin from the tumor tissues, and the samples were placed in proteinase K. Genomic DNA was extracted using a QIAamp DNA formalin-fixed paraffin-embedded tissue kit (Qiagen, Hilden, Germany) according to the manufacturer's instructions. Subsequently, EGFR exons 18-21 were amplified by nested polymerase chain reaction and subjected to pyrosequencing. The polymerase chain reaction products were analyzed by electrophoresis in 3\% agarose gel to confirm successful amplification. The pyrosequencing assay was performed using the PyroMark Q24 ID system (Qiagen) following the manufacturer's protocols. Samples harboring mutations were resequenced using the same test conditions.

\section{Evaluation methods}

Based on the Response Evaluation Criteria in Solid Tumors (RECIST) 1.1 guidelines, ${ }^{15}$ the response to treatment was classified as a complete response, partial response, stable disease, or progression of disease. Complete response and partial response were defined as the response rate, and complete response, partial response, and stable disease were defined as the disease control rate.

\section{Follow-up}

Follow-up was undertaken in all patients. The last follow-up was in January 2014, and the median duration of follow-up was 25.1 months. Overall survival was defined as the time from the date of receiving the first-line chemotherapy to death or last follow-up. Progression-free survival was defined as the time from the date of receiving the first-line chemotherapy to disease progression or death.

\section{Statistical analysis}

The statistical analysis was performed using Statistical Package for the Social Sciences version 17.0 software (SPSS Inc., Chicago, IL, USA). Rates were compared using the $\chi^{2}$ test. Fisher's exact test was used to analyze categorical variables. Median progression-free survival was calculated using the Kaplan-Meier method. The Cox regression model was used to identify independent prognostic factors for advanced NSCLC. We used the Kaplan-Meier method to draw survival curves and tested these by log-rank. Twosided $P$-values $<0.05$ were considered to be statistically significant.

\section{Results}

\section{Patient characteristics}

Patient characteristics are shown in Table 1. The research cohort comprised 266 NSCLC patients of median age 57 (range 28-81) years, with $53.4 \%$ being male. One hundred and eighty patients had stage IV disease (67.7\%), and 242 had adenocarcinoma (91.0\%). The most common 
Table I Relationship between clinical characteristics and EGFR mutation state

\begin{tabular}{|c|c|c|c|}
\hline Characteristics & EGFR mutation & EGFR wild-type & $P$ \\
\hline No of patients & 121 & 145 & \\
\hline Age (range) & $57(3 \mathrm{I}-77)$ & $57(28-8 I)$ & \\
\hline \multicolumn{4}{|l|}{ Sex } \\
\hline Male & 58 (47.9\%) & 84 (57.9\%) & 0.104 \\
\hline Female & $63(52.1 \%)$ & 61 (42.1\%) & \\
\hline \multicolumn{4}{|l|}{ Smoking history } \\
\hline Yes & 32 (26.4\%) & $82(56.6 \%)$ & $<0.001$ \\
\hline No & 89 (73.6\%) & $63(43.4 \%)$ & \\
\hline \multicolumn{4}{|l|}{ ECOG } \\
\hline 0 & $21(17.4 \%)$ & 27 (I8.6\%) & 0.789 \\
\hline I & $100(82.6 \%)$ & $118(81.4 \%)$ & \\
\hline \multicolumn{4}{|l|}{ Histologic type } \\
\hline Adenocarcinoma & II 17 (96.7\%) & 125 (86.2\%) & 0.003 \\
\hline $\begin{array}{l}\text { Squamous cell } \\
\text { carcinoma }\end{array}$ & $4(3.3 \%)$ & $20(13.8 \%)$ & \\
\hline \multicolumn{4}{|l|}{ Weight loss } \\
\hline$\geq 5 \%$ & 14 (II.6\%) & $20(13.8 \%)$ & 0.589 \\
\hline$<5 \%$ & $107(88.4 \%)$ & $125(86.2 \%)$ & \\
\hline \multicolumn{4}{|l|}{ Clinical stage } \\
\hline IIIB & 42 (34.7\%) & 44 (30.3\%) & 0.448 \\
\hline IV & 79 (65.3\%) & IOI (69.7\%) & \\
\hline \multicolumn{4}{|c|}{ Chemotherapeutic regimen } \\
\hline Gemcitabine & 26 & 30 & \\
\hline Docetaxel & 21 & 41 & \\
\hline Vinorelbine & 31 & 19 & \\
\hline Pemetrexed & 43 & 55 & \\
\hline \multicolumn{4}{|l|}{ Response } \\
\hline$C R+P R$ & 39 (32.2\%) & $4 \mathrm{I}(28.3 \%)$ & 0.484 \\
\hline $\mathrm{SD}+\mathrm{PD}$ & $82(67.8 \%)$ & 104 (71.7\%) & \\
\hline \multicolumn{4}{|l|}{ After first-line } \\
\hline Received TKIs & 58 (47.9\%) & $24(16.6 \%)$ & $<0.001$ \\
\hline Unreceived TKIs & $63(52.1 \%)$ & 121 (83.4\%) & \\
\hline
\end{tabular}

Abbreviations: EGFR, epidermal growth factor receptor; ECOG, Eastern Cooperative Oncology Group; CR, complete response; PR, partial response; $\mathrm{SD}$, stable disease; PD, progression of disease; TKls, tyrosine kinase inhibitors.

sites of metastasis were the lung $(33.3 \%, 60 / 180)$, pleura $(26.7 \%, 48 / 180)$, bone $(24.4 \%, 44 / 180)$, brain $(21.1 \%$, $38 / 180)$, and liver $(15.6 \%, 28 / 180)$. All patients were treated with platinum-based doublet chemotherapy as firstline treatment, with gemcitabine, docetaxel, vinorelbine, and pemetrexed regimens administered in 56 (21.1\%), 62 (23.3\%), 50 (18.8\%), and 98 patients (36.8\%), respectively. After first-line chemotherapy, 82 patients received an EGFR TKI as second-line or third-line therapy, while 106 cases received continuous chemotherapy. EGFR mutations were identified in 121 patients (45.5\%). Sixty-four patients $(52.9 \%)$ harbored in-frame deletions in exon 19 , which were caused by loss of codons 746-750 (delE746-A750). Fifty patients $(41.3 \%)$ had tumors harboring amino acid replacements in exon 21, ie, leucine to arginine at codon 858 (L858R). Exon 18 (G719S) and exon 20 (T790M) mutations were found in five $(4.1 \%)$ and two $(1.7 \%)$ patients, respectively. There were more women $(50.8 \%, 63 / 124)$ than men $(40.8 \%, 58 / 142)$, more nonsmokers $(58.6 \%, 89 / 152)$ than smokers $(28.1 \%, 32 / 114)$, more patients with an Eastern Cooperative Oncology Group performance status of $1(45.9 \%, 100 / 218)$ than $0(43.8 \%, 21 / 48)$, and more with a weight loss of $<5 \%(46.1 \%, 107 / 232)$ than a weight loss $\geq 5 \%(41.2 \%, 14 / 34)$.

\section{Association of EGFR mutations with response to first-line chemotherapy}

All 266 patients were treated with platinum-based regimens. In these patients, a partial response was documented in $30.1 \%$ $(80 / 266)$, stable disease in 51.1\% (136/266), and progression of disease in $18.8 \%(50 / 266)$. The overall response and disease control rates were $30.1 \%$ and $81.2 \%$, respectively. In 145 patients with wild-type $E G F R$, the response rate and disease control rate were $28.3 \%$ and $83.4 \%$, respectively. No differences in response rate or disease control rate were found when gemcitabine-based, docetaxel-based, vinorelbine-based, and pemetrexed-based treatments were compared $(30.0 \%$ versus $29.3 \%, 26.3 \%, 27.3 \%$, and $76.7 \%$, $85.4 \%, 84.2 \%$, and $85.5 \%$, respectively). We found that carriers of the EGFR mutation had a response rate of $32.2 \%$ to chemotherapy, which was similar to the $28.3 \%$ for wildtype $E G F R$ carriers $(P=0.484)$. The disease control rate was $78.5 \%$. No differences in response rate were found between gemcitabine-based, docetaxel-based, vinorelbine-based, and pemetrexed-based therapy in 121 patients with EGFR mutations (34.6\% versus $28.6 \%, 29.0 \%$, and $34.9 \%$ ). However, the disease control rate was higher in pemetrexed-treated patients than in vinorelbine-treated patients $(90.7 \%$ versus $58.1 \%$, respectively, $P=0.001)$. Further, although not significantly different, the response rates for the exon 19 mutation and the exon 21 mutation were 37.5\% (24/64) and $24.0 \%(12 / 50, P=0.124)$. Differences in characteristics and response to chemotherapy between patients who received gemcitabine-based, docetaxel-based, vinorelbine-based, and pemetrexed-based therapies are shown according to EGFR status in Table 2.

\section{Relationship between EGFR mutation and survival}

The median progression-free survival for the 266 patients was 5.7 months (95\% confidence interval [CI] 5.4-6.0), the median survival time was 16.8 months, and the 1-year and 2-year overall survival was $72.2 \%$ and $28.6 \%$, respectively. There was a significant difference in progression-free 
Table 2 Characteristics of patients receiving different regimens and the response to chemotherapy according to EGFR status

\begin{tabular}{|c|c|c|c|c|c|c|c|c|}
\hline \multirow[t]{2}{*}{ Characteristics } & \multicolumn{4}{|c|}{ EGFR mutations } & \multicolumn{4}{|c|}{ Wild-type EGFR } \\
\hline & Gemcitabine & Docetaxel & Vinorelbine & Pemetrexed & Gemcitabine & Docetaxel & Vinorelbine & Pemetrexed \\
\hline No of patients & 26 & 21 & 31 & 43 & 30 & 41 & 19 & 55 \\
\hline Age (median years) & 58 & 59 & 58 & 55 & 54 & 58 & 59 & 56 \\
\hline \multicolumn{9}{|l|}{ Sex } \\
\hline Male & 9 & 12 & 14 & 23 & 27 & 20 & 8 & 29 \\
\hline Female & 17 & 9 & 17 & 20 & 3 & 21 & 11 & 26 \\
\hline \multicolumn{9}{|l|}{ Smoking history } \\
\hline Yes & 4 & 2 & 14 & 12 & 22 & 22 & 16 & 22 \\
\hline No & 22 & 19 & 17 & 31 & 8 & 19 & 3 & 33 \\
\hline \multicolumn{9}{|l|}{ Histologic type } \\
\hline Adenocarcinoma & 25 & 19 & 30 & 43 & 21 & 33 & 16 & 55 \\
\hline $\begin{array}{l}\text { Squamous cell } \\
\text { carcinoma }\end{array}$ & 1 & 2 & 1 & 0 & 9 & 8 & 3 & 0 \\
\hline \multicolumn{9}{|l|}{ Clinical stage } \\
\hline IIIB & 10 & 8 & 12 & 12 & 16 & 10 & 8 & 10 \\
\hline IV & 16 & 13 & 19 & 31 & 14 & 31 & II & 45 \\
\hline \multicolumn{9}{|l|}{ Response } \\
\hline CR & 0 & 0 & 0 & 0 & 0 & 0 & 0 & 0 \\
\hline PR & 9 & 6 & 9 & 15 & 9 & 12 & 5 & 15 \\
\hline SD & 12 & II & 9 & 24 & 14 & 23 & II & 32 \\
\hline PD & 5 & 4 & 13 & 4 & 7 & 6 & 3 & 8 \\
\hline
\end{tabular}

Abbreviations: EGFR, epidermal growth factor receptor; CR, complete response; PR, partial response; SD, stable disease; PD, progression of disease.

survival between patients with $E G F R$ mutation and those with $E G F R$ wild-type (6.1 versus 5.0 months, respectively, $P=0.004$, Figure 1). EGFR mutation was found in patients with a longer median survival time (18.9 months, 95\% CI 18-19.8) and 1-year and 2-year overall survival (81.0\% and $33.9 \%$, respectively) when compared with wild-type $E G F R$

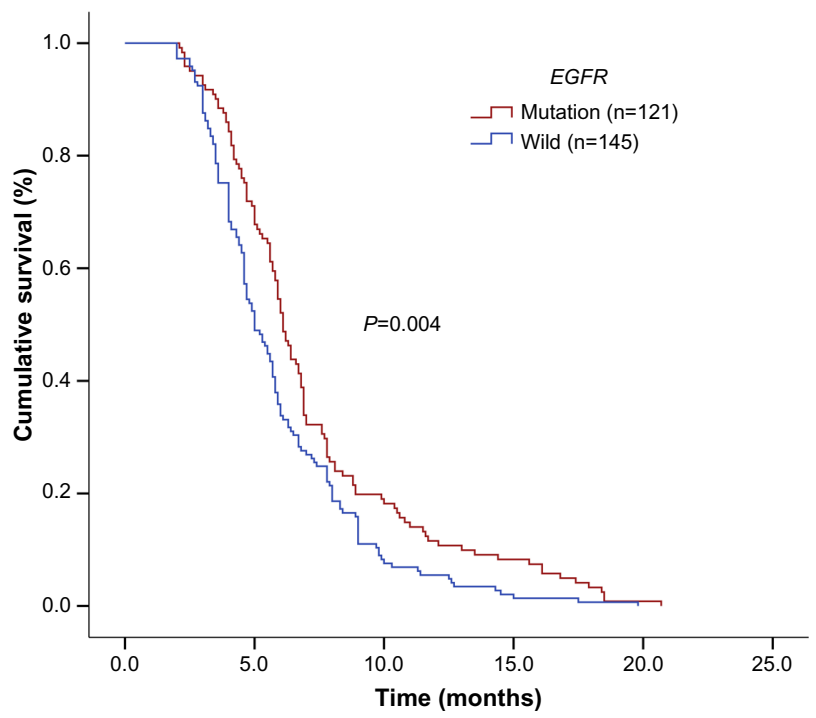

Figure I Kaplan-Meier estimates of progression-free survival according to EGFR status (EGFR mutation and EGFR wild-type).

Note: Kaplan-Meier analysis showed that NSCLC patients with EGFR mutations had longer progression-free survival than EGFR wild-type patients (6.I versus 5.0 months, $P=0.004$ ).

Abbreviations: EGFR, epidermal growth factor receptor; NSCLC, non-small cell lung cancer. patients (13.8 months, 95\% CI 12.7-15.1, and 63.4\% and $22.8 \%$, respectively, $P=0.001$, Figure 2). Patients with the EGFR exon 19 mutation had longer progression-free survival than those with the EGFR exon 21 mutation $(P=0.007)$. Patients with the EGFR exon 19 mutation had a longer median survival time and 1-year and 2-year overall survival

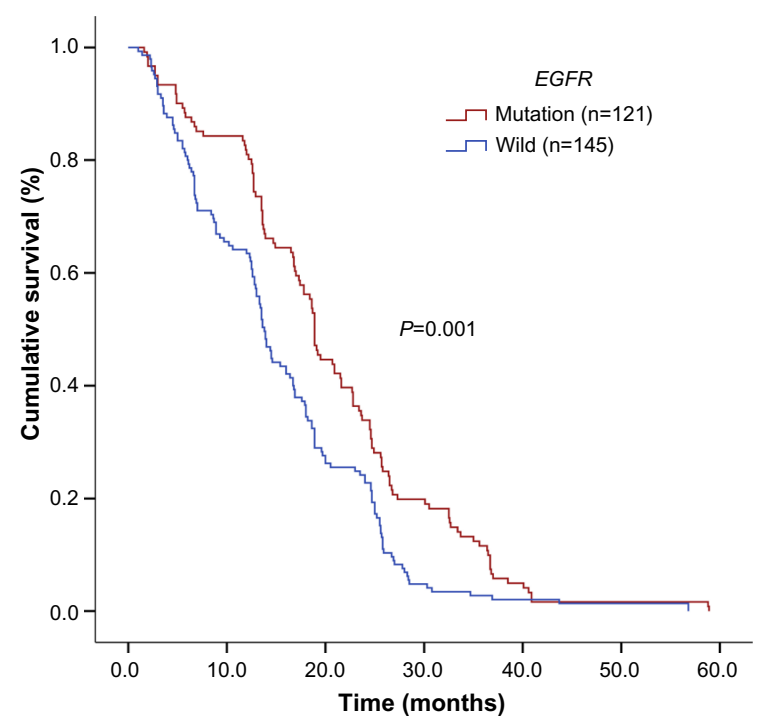

Figure 2 Kaplan-Meier estimates of overall survival according to EGFR status (EGFR mutation and EGFR wild-type).

Note: Kaplan-Meier analysis showed that NSCLC patients with EGFR mutation had longer overall survival than EGFR wild-type patients (I8.9 versus I3.8 months, $P=0.00 \mathrm{I})$.

Abbreviations: EGFR, epidermal growth factor receptor; NSCLC, non-small cell lung cancer. 
than those with the EGFR exon 21 mutation (19.2 months, $90.6 \%$, and $37.5 \%$ versus 17.8 months, $70.0 \%$, and $30.0 \%$, respectively), but the difference was not statistically significant $(P=0.908)$. Moreover, in 180 patients with stage IV disease, those with EGFR mutation had a longer median survival time, and better 1-year and 2-year survival rates, than those with wild-type $E G F R(P=0.028)$. The relationship between clinical characteristics, EGFR mutation state, and survival is shown in Table 3.

In $E G F R$ wild-type patients, there were no statistically significant differences in progression-free survival between the gemcitabine-based, docetaxel-based, vinorelbine-based, and pemetrexed-based treatments (5.7 months versus 4.6, 5.6, and 4.9 months, respectively, $P=0.946$, Figure 3). Further, there was no statistically significant difference in progressionfree survival between the four treatment groups in patients with EGFR mutation (6.0 months versus 6.3, 6.4, and 5.9 months, $P=0.814$, Figure 4 ).

Univariate analysis of various prognostic factors, and the data showed that the important ones were clinical stage $(P=0.001)$, response to first-line chemotherapy $(P=0.001)$, histological type $(P=0.008)$, whether TKIs were received after first-line chemotherapy $(P=0.023)$, and $E G F R$ mutation status $(P=0.001)$. Cox multivariate

Table 3 Results of the univariate analysis of EGFR mutation with prognosis

\begin{tabular}{llllll}
\hline & No & MST & IYOS & 2YOS & $P$ \\
\hline $\begin{array}{l}\text { Total } \\
\text { EGFR }\end{array}$ & 266 & 16.8 & $72.2 \%$ & $28.6 \%$ & \\
$\quad$ Mutation & 121 & 18.9 & $81.0 \%$ & $33.9 \%$ & 0.00 I \\
$\quad$ Wild & 145 & 13.8 & $63.4 \%$ & $22.8 \%$ & \\
EGFR mutation & & & & & \\
$\quad$ I9 exon & 64 & 19.2 & $90.6 \%$ & $37.5 \%$ & 0.908 \\
$\quad$ II exon & 50 & 17.8 & $70.0 \%$ & $30.0 \%$ & \\
After first-line & & & & & \\
$\quad$ Received TKIs & 82 & 19.5 & $83.0 \%$ & $36.6 \%$ & 0.023 \\
$\quad$ Unreceived TKIs & 184 & 13.9 & $67.4 \%$ & $25.0 \%$ & \\
Histologic type & & & & & \\
$\quad$ Adenocarcinoma & 242 & 16.2 & $78.8 \%$ & $30.8 \%$ & 0.008 \\
$\quad$ Squamous cell & 24 & 18.4 & $80.3 \%$ & $35.3 \%$ & \\
$\quad$ carcinoma & & & & & \\
Clinical stage & & & & & \\
$\quad$ IIIB & 86 & 19.6 & $81.4 \%$ & $45.3 \%$ & $<0.00$ I \\
$\quad$ IV & 180 & 13.9 & $67.8 \%$ & $20.6 \%$ & \\
Response to first-line & & & & & \\
$\quad$ CR + PR & 80 & 20.5 & $90.0 \%$ & $48.8 \%$ & $<0.00$ I \\
SD + PD & 186 & 14.0 & $64.5 \%$ & $21.0 \%$ & \\
\hline
\end{tabular}

Abbreviations: EGFR, epidermal growth factor receptor; TKIs, tyrosine kinase inhibitors; CR, complete response; PR, partial response; SD, stable disease; PD, progression of disease; MST, median survival time; YOS, year overall survival.

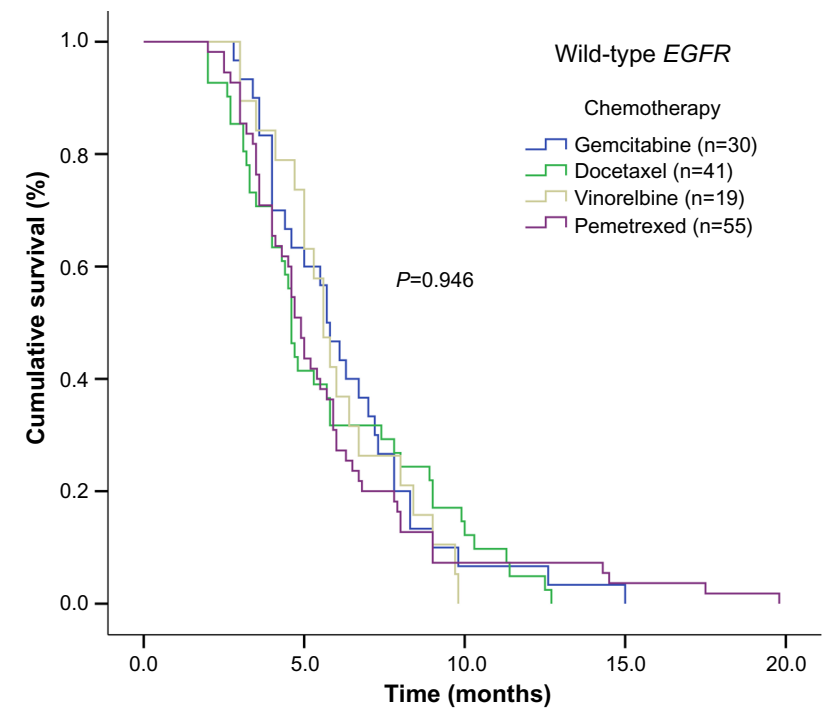

Figure 3 Kaplan-Meier estimates of progression-free survival for gemcitabinebased, docetaxel-based, vinorelbine-based, and pemetrexed-based treatments in wild-type EGFR patients.

Note: Kaplan-Meier analysis showed that there were no statistically significant differences in progression-free survival among gemcitabine-based, docetaxel-based, vinorelbine-based, and pemetrexed-based treatments in wild-type EGFR patients ( 5.7 versus 4.6 versus 5.6 versus $4.9, P=0.946$ ).

Abbreviation: EGFR, epidermal growth factor receptor.

regression analysis was used to determine underlying factors influencing survival, eg, age, sex, smoking history, Eastern Cooperative Oncology Group status, histological diagnosis, weight loss, whether TKIs are received after first-line chemotherapy, tumor stage, EGFR mutation,

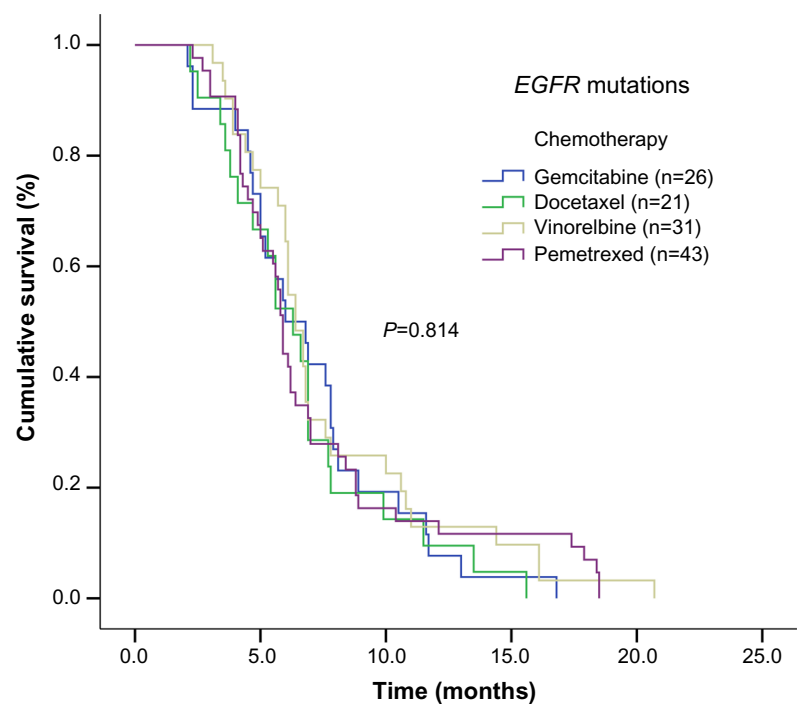

Figure 4 Kaplan-Meier estimates of progression-free survival for gemcitabine-, docetaxel-, vinorelbine- and pemetrexed-based treatments in patients with EGFR mutations.

Note: Kaplan-Meier analysis showed there were no statistical differences in progression-free survival among gemcitabine-based, docetaxel-based, vinorelbinebased, and pemetrexed-based treatments in patients with EGFR mutation (6.0 months versus $6.3,6.4$, and 5.9 months, $P=0.8 \mid 4$ ).

Abbreviation: EGFR, epidermal growth factor receptor. 
and the efficacy of first-line chemotherapy. The results showed that response to front-line chemotherapy and EGFR mutation status were independent prognostic factors (Table 4).

\section{Relationship between EGFR mutation and response to first-line chemotherapy and survival in KRAS wild-type patients}

Among the 266 cases, a subgroup of 83 patients was evaluated for Kirsten rat sarcoma viral oncogene homolog (KRAS) mutation status. Twenty patients (24.1\%) had KRAS mutation and 63 (75.9\%) were $K R A S$ wild-type. $K R A S$ wild-type patients with $E G F R$ mutation responded better to first-line chemotherapy (46.2\% versus $20.8 \%, P=0.043$ ) and longer progression-free survival (7.0 months versus 4.6 months, $P=0.042$, Figure 5).

\section{Relationship between EGFR mutation and response to second-line treatment}

After failure of first-line chemotherapy, 82 patients accepted EGFR TKIs (as second-line chemotherapy in 62 cases and as third-line chemotherapy in 20 cases). The remaining 106 patients continued their systemic chemotherapy, while 78 decided not to continue treatment. Compared with those who did not receive TKI therapy, patients who accepted EGFR TKIs had a statistically significant increase in longterm survival $(P=0.023)$. Comparing patients treated with EGFR TKIs $(n=62)$ and those given conventional chemotherapy $(n=106)$ as their second-line therapeutic regimen, we did not find a statistically significant difference in median survival time (21.6 months versus 18.0 months, respectively, $P=0.573)$.

\section{Discussion}

These data show that active EGFR mutations portend a longer survival time in patients with advanced NSCLC, especially those with the exon 19 mutation. KRAS wildtype patients with the EGFR mutation responded better to first-line chemotherapy, and EGFR mutation and curative first-line chemotherapy were independent prognostic factors for advanced NSCLC.

Platinum-based doublet chemotherapy is presently the most common first-line treatment for advanced NSCLC. ${ }^{11,12}$ Therefore, it is important to explore the relationship between $E G F R$ mutation, effect of chemotherapy, and clinical outcome. The relationship between EGFR mutation status and response to chemotherapy is not well understood. Kalikaki et $\mathrm{al}^{16}$ reported that chemotherapy was more effective in patients with $E G F R$ mutation than in $E G F R$ wild-type patients $(P=0.023)$. The Iressa Pan-Asia Study ${ }^{17}$ indicated that the response rate was higher in the patients with EGFR mutations compared with wild-type EGFR cases who received paclitaxel/carboplatin as the first-line chemotherapy (47.3\% versus $23.5 \%$ ). A study reported by Lee et $\mathrm{al}^{9}$ found no obvious relationship between presence of $E G F R$ mutation and the effectiveness of first-line chemotherapy. However, a recent Japanese study indicated that patients with the EGFR mutation were less sensitive to docetaxel than those with wild-type $E G F R \cdot{ }^{10}$ Our study showed that the response rate and disease control rate of the first-line chemotherapy platinum containing regimens were both higher in patients with the EGFR mutation than in patients with $E G F R$ wild-type in advanced NSCLC. No statistically significant differences were found between these two groups, which is probably due to the small sample size. However, we did find that patients with the

Table 4 Cox proportional hazards model for progression-free survival and overall survival

\begin{tabular}{|c|c|c|c|c|c|c|}
\hline \multirow[t]{2}{*}{ Factors } & \multicolumn{3}{|c|}{ Progression-free survival } & \multicolumn{3}{|c|}{ Overall survival } \\
\hline & HR & $95 \% \mathrm{Cl}$ & $\boldsymbol{P}$ & HR & $95 \% \mathrm{Cl}$ & $P$ \\
\hline Age & 0.998 & $0.986-1.009$ & 0.694 & 0.995 & $0.984-1.006$ & 0.391 \\
\hline Sex (male vs female) & 1.176 & $0.906-1.526$ & 0.223 & 1.196 & $0.914-1.565$ & 0.192 \\
\hline Smoking history (yes vs no) & $\mathrm{I} .144$ & $0.858-1.526$ & 0.359 & 1.012 & $0.758-|.35|$ & 0.935 \\
\hline ECOG (I vs 0$)$ & $\mathrm{I} .188$ & $0.817-1.726$ & 0.367 & $\mathrm{I} .357$ & $0.93 I-1.978$ & 0.112 \\
\hline $\begin{array}{l}\text { Histologic type (adenocarcinoma vs } \\
\text { squamous cell carcinoma) }\end{array}$ & 1.301 & $0.832-2.035$ & 0.249 & 1.498 & $0.914-2.455$ & 0.109 \\
\hline Weight loss ( $\geq 5 \%$ vs $<5 \%$ ) & $\mathrm{I} .088$ & $0.678-1.746$ & 0.728 & $\mathrm{I} .142$ & $0.698-1.869$ & 0.596 \\
\hline EGFR mutation (yes vs no) & 0.661 & $0.487-0.898$ & 0.008 & 0.649 & $0.48 I-0.875$ & 0.005 \\
\hline $\begin{array}{l}\text { Response to the front-line chemotherapy } \\
\text { (CR + PR vs SD + PD) }\end{array}$ & 0.552 & $0.4|2-0.74|$ & $<0.001$ & 0.523 & $0.390-0.700$ & $<0.001$ \\
\hline $\begin{array}{l}\text { Whether receiving TKIs after first-line } \\
\text { chemotherapy (yes vs no) }\end{array}$ & 0.852 & $0.638-1.138$ & 0.278 & 0.893 & $0.673-1.185$ & 0.434 \\
\hline Clinical stage (IIIB vs IV) & 0.826 & $0.622-1.097$ & 0.186 & 0.854 & $0.633-1.153$ & 0.304 \\
\hline
\end{tabular}

Abbreviations: vs, versus; EGFR, epidermal growth factor receptor; ECOG, Eastern Cooperative Oncology Group; CR, complete response; PR, partial response; SD, stable disease; PD, progression of disease; TKIs, tyrosine kinase inhibitors; HR, hazard ratio; $\mathrm{Cl}$, confidence interval. 


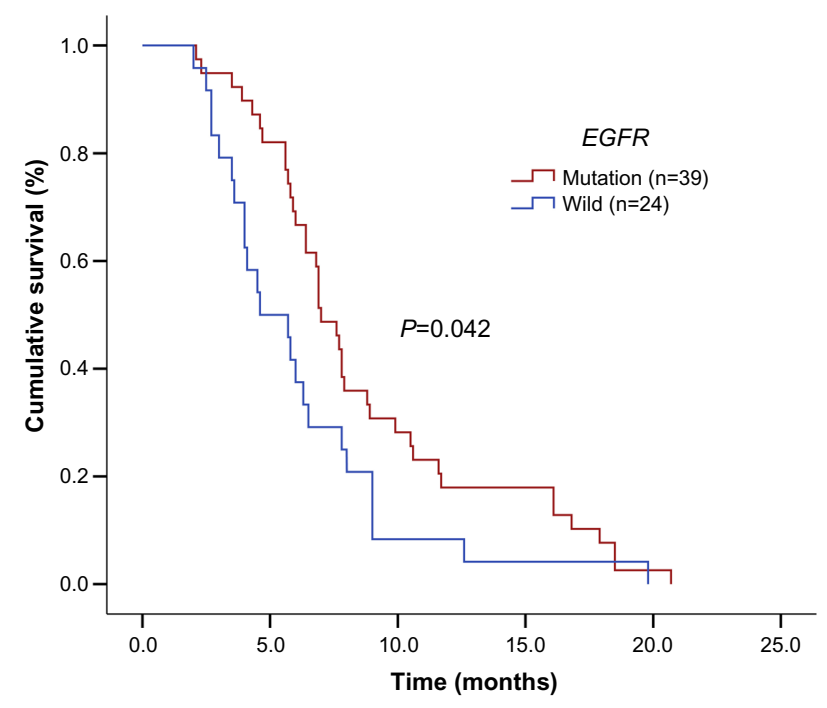

Figure 5 Kaplan-Meier estimates of progression-free survival according to EGFR mutation status (EGFR mutation and EGFR wild-type) in wild-type KRAS patients.

Note: Kaplan-Meier analysis showed NSCLC patients with EGFR mutations had a longer progression-free survival than EGFR wild-type patients in wild-type KRAS patients (7.0 versus 4.6 months, $P=0.042$ )

Abbreviations: EGFR, epidermal growth factor receptor; KRAS, Kirsten rat sarcoma viral oncogene homolog; NSCLC, non-small cell lung cancer.

EGFR mutation responded better to first-line chemotherapy (46.2\% versus $20.8 \%, P=0.043$ ) and a longer progression-free survival ( 7.0 months versus 4.6 months, $P=0.042$ ) than those without $E G F R$ mutation in $K R A S$ wild-type patients. Earlier research ${ }^{18}$ showed that patients with the $K R A S$ mutation had shorter survival than their $K R A S$ wild-type counterparts, suggesting that $K R A S$ mutation and $E G F R$ mutation might have opposing effects. Both the EGFR and KRAS genes predict the prognosis of NSCLC. ${ }^{19,20}$

Exon 19 deletion mutation and a mutation in exon 21 (L858R) are the two main types of EGFR mutation. Riely et $\mathrm{al}^{21}$ found that patients with the EGFR exon 19 mutation had a longer median survival time than those with the EGFR exon 21 mutation after receiving gefitinib or erlotinib (34 versus 8 months, respectively; $P=0.01$, log-rank). Park et al ${ }^{22}$ investigated 217 patients with NSCLC and found that those with EGFR mutations who received paclitaxel had a better disease control rate and longer progression-free survival, which was more pronounced in patients with the exon 19 deletion mutation. Cappuzzo et $\mathrm{al}^{8}$ found no clear relationship between EGFR mutation status and the effectiveness of first-line chemotherapy, but patients with the exon 19 mutation showed a higher objective response rate after receiving chemotherapy $(46.6 \%$ versus $0 \%, P=0.02$ ). Our research also indicates that patients with the exon 19 deletion mutation had a longer survival time after first-line platinum-based chemotherapy than those with the exon 21 mutation $(P=0.007)$. Further, the effectiveness of first-line chemotherapy was greater in patients with the exon 19 mutation than in those with the exon 21 mutation $(37.5 \%$ versus $24.0 \%, P=0.124)$, but the difference was not statistically significant.

Pemetrexed is a new-generation multitargeted antifolate agent that maintains tumor cell division in $\mathrm{S}$ phase by destroying the folate-dependent metabolic pathway within the cells, thereby limiting tumor growth. ${ }^{23}$ Pemetrexed is now the preferred second-line treatment for NSCLC in the USA. ${ }^{24}$ In recent years, clinical researchers had demonstrated the positive effects of this agent in advanced NSCLC, and pemetrexed has gradually become a first-line agent for treatment of the disease. ${ }^{23}$ Meanwhile, there is some prospective and retrospective evidence ${ }^{25,26}$ from Phase III research showing longer overall survival in patients with nonsquamous NSCLC treated with pemetrexed than in their counterparts treated with gemcitabine or docetaxel. These observations indicate that pemetrexed had higher activity in nonsquamous cell cancer. In the present study, we found that the disease control rate was higher for pemetrexed-based chemotherapy than for vinorelbine-based chemotherapy in patients with EGFR mutation. However, we cannot conclude that EGFR mutation improves the sensitivity to pemetrexed, because our results might have arisen from the fact that the majority of our patients with the EGFR mutation had adenocarcinoma of the lung $(96.7 \%, 117 / 121)$ and pemetrexed has been shown to be more effective than other chemotherapeutic agents in this type of cancer. ${ }^{25,26}$ Our retrospective analysis has some limitations, and there remains a need for prospective research in large samples to resolve whether EGFR mutation could improve the sensitivity to pemetrexed in advanced NSCLC patients.

Our analysis of survival in 266 patients with NSCLC indicates that those with $E G F R$ mutations had longer progression-free survival than those with wild-type EGFR. This finding is similar to that of Hotta et al, ${ }^{27}$ who analyzed survival data in 194 patients and found that patients with EGFR mutation had longer progression-free survival. However, other researchers have reported that EGFR mutation status has no impact on the effect of chemotherapy or longterm survival. ${ }^{9}$ The current research analyzed the relationship between EGFR mutation status and progression-free survival, and indicated that EGFR mutation had a greater survival benefit when compared with wild-type status $(P=0.004)$. Multifactorial analysis revealed that EGFR mutation and efficacy of first-line chemotherapy were independent prognostic factors in patients with advanced NSCLC, which is consistent with the results of other research. ${ }^{28}$ 
Currently, the international recommendations for secondline treatment are docetaxel, pemetrexed, and EGFR TKIs. One hundred and forty-six patients were included in the Phase III INTEREST (Gefitinib versus docetaxel in previously treated non-small-cell lung cancer) trial, ${ }^{29}$ the main aim of which was to compare overall survival between gefitinib and docetaxel by testing for noninferiority. Overall survival was 7.6 months in the gefitinib group and 8.0 months in the docetaxel group, and the 1-year survival rate was $32 \%$ and $34 \%$, respectively (hazards ratio $1.020,96 \%$ CI 0.905-1.150), which met the preset requirement that the hazards ratio be $<1.154$. Gefitinib was significantly higher than that of docetaxel in the quality of life improvement, drug safety, and tolerability. The results of this study, albeit not reaching statistical significance, indicate that survival time in patients with advanced NSCLC is longer with second-line use of EGFR TKIs when compared with conventional chemotherapy.

\section{Conclusion}

Our research indicates that active $E G F R$ mutations mean higher survival time for patients with advanced NSCLC who receive platinum-based doublet first-line chemotherapy, especially those with the exon 19 deletion mutation. Among $K R A S$ wild-type patients, those with EGFR mutation responded better to first-line chemotherapy. In this study, EGFR mutation and a curative effect of first-line chemotherapy were independent prognostic factors in advanced NSCLC.

\section{Disclosure}

The authors report no conflicts of interest in this work.

\section{References}

1. Ferlay J, Shin HR, Bray F, Forman D, Mathers C, Parkin DM. Estimates of worldwide burden of cancer in 2008: GLOBOCAN 2008. Int J Cancer. 2010;127:2893-2917.

2. Le Péchoux C. Role of postoperative radiotherapy in resected non-small cell lung cancer: a reassessment based on new data. Oncologist. 2011;16:672-681.

3. Wu M, Zhao J, Song SW, et al. EGFR mutations are associated with prognosis but not with the response to front-line chemotherapy in the Chinese patients with advanced non-small cell lung cancer. Lung Cancer. 2010;67:343-347.

4. Mok TS, Wu YL, Thongprasert S, et al. Gefitinib or carboplatin-paclitaxel in pulmonary adenocarcinoma. $N$ Engl J Med. 2009;361:947-957.

5. Petrelli F, Borgonovo K, Cabiddu M, et al. Efficacy of EGFR tyrosine kinase inhibitors in patients with EGFR-mutated non-small-cell lung cancer: a meta analysis of 13 randomized trials. Clin Lung Cancer. 2012;2:107-114.

6. Giaccone G, Herbst RS, Manegold C, et al. Gefitinib in combination with gemcitabine and cisplatin in advanced non-small-cell lung cancer: a phase III trial-INTACT 1. J Clin Oncol. 2004;22:777-784.

7. Gatzemeier U, Pluzanska A, Szczesna A, et al. Phase III study of erlotinib in combination with cisplatin and gemcitabine in advanced non-small-cell lung cancer: the Tarceva Lung Cancer Investigation Trial. J Clin Oncol. 2007;25:1545-1552.
8. Cappuzzo F, Ligorio C, Toschi L, et al. EGFR and HER2 gene copy number and response to first-line chemotherapy in patients with advanced non-small cell lung cancer (NSCLC). J Thorac Oncol. 2007;2:423-429.

9. Lee KH, Han SW, Hwang PG, et al. Epidermal growth factor response to chemotherapy in patients with non-small-cell lung cancer. Jpn J Clin Oncol. 2006;36:334-350.

10. Yoshimasu T, Oura S, Ohta F, et al. Epidermal growth factor receptor mutations are associated with docetaxel sensitivity in lung cancer. J Thorac Oncol. 2011;6:1658-1662.

11. Pfister DG, Johnson DH, Azzoli CG, et al. American Society of Clinical Oncology treatment of unresectable non-small-cell lung cancer guideline: update 2003. J Clin Oncol. 2004;22:330-353.

12. Schiller JH, Harrington D, Belani CP, et al. Comparison of four chemotherapy regimens for advanced non-small-cell lung cancer. N Engl J Med. 2002;346:92-98.

13. Oken MM, Creech RH, Tormey DC, et al. Toxicity and response criteria of the Eastern Cooperative Oncology Group. Am J Clin Oncol. 1982;5:649-655.

14. Dufort S, Richard MJ, Lantuejoul S, de Fraipont F. Pyrosequencing, a method approved to detect the two major EGFR mutations for anti EGFR therapy in NSCLC. J Exp Clin Cancer Res. 2011;30:57.

15. Eisenhauer EA, Therasse P, Bogaerts J, et al. New response evaluation criteria in solid tumours: revised RECIST guideline (version 1.1). Eur $J$ Cancer. 2009;45(2):228-247.

16. Kalikaki A, Koutsopoulos A, Hatzidaki D, et al. Clinical outcome of patients with non-small cell lung cancer receiving front-line chemotherapy according to EGFR and K-RAS mutation status. Lung Cancer. 2010;69:110-115.

17. Lynch TJ, Bell DW, Sordella R, et al. Activating mutations in the epidermal growth factor receptor underlying responsiveness of non-small-cell lung cancer to gefitinib. $N$ Engl J Med. 2004;350: 2129-2139.

18. Johnson ML, Sima CS, Chaft J, et al. Association of KRAS and EGFR mutations with survival in patients with advanced lung adenocarcinomas. Cancer. 2013;119:356-362.

19. Eberhard DA, Johnson BE, Amler LC, et al. Mutations in the epidermal growth factor receptor and in KRAS are predictive and prognostic indicators in patients with non-small-cell lung cancer treated with chemotherapy alone and in combination with erlotinib. J Clin Oncol. 2005;23:5900-5909.

20. Pirker R, Pereira JR, von Pawel J, et al. EGFR expression as a predictor of survival for first-line chemotherapy plus cetuximab in patients with advanced non-small cell lung cancer: analysis of data from the phase 3 FLEX study. Lancet Oncol. 2012;1:33-42.

21. Riely GJ, Pao W, Pham DK, et al. Clinical course of patients with nonsmall cell lung cancer and epidermal growth factor receptor exon 19 and exon 21 mutations treated with gefitinib or erlotinib. Clin Cancer Res. 2006;12:839-844.

22. Park JH, Lee SH, Keam B, et al. EGFR mutations as a predictive marker of cytotoxic chemotherapy. Lung Cancer. 2012;77:433-437.

23. Demarinis F, Paul S, Hanna N, et al. Survival update for the phase III study of pemetrexed versus docetaxel in non-small-cell lung cancer. J Clin Oncol. 2006;18:2241-2245.

24. Moro-Sibilot D, Vergneneqre A, Smit EF, et al. Second-line therapy for NSCLC in clinical practice: baseline results of the European SELECTION observational study. Curr Med Res Opin. 2010;26: 2661-2672.

25. Scagliotti GV, Parikh P, von Pawel J, et al. Phase III study comparing cisplatin plus gemcitabine with cisplatin plus pemetrexed in chemotherapy-naive patients with advanced-stage non-small-cell lung cancer. J Clin Oncol. 2008;26:3543-3551.

26. Peterson P, Simms L, Park K, et al. Is pemetrexed more effective in patients with non-squamous histology? A retrospective analysis of a phase III trial of pemetrexed versus docetaxel in previously treated patients with advanced non-small cell lung cancer (NSCLC). Eur J Cancer. 2007;5:363-364. 
27. Hotta K, Kiura K, Toyooka S, et al. Clinical significance of epidermal growth factor receptor gene mutations on treatment outcome after firstline cytotoxic chemotherapy in Japanese patients with non-small cell lung cancer. J Thorac Oncol. 2007;2:632-637.

28. Sutani A, Nagai Y, Udagawa K, et al. Gefitinib for non-small-cell lung cancer patients with epidermal growth factor receptor gene mutations screened by peptide nucleic acid-locked nucleic acid PCR clamp. Br J Cancer. 2006;95:1483-1489.
29. Kim ES, Hirsh V, Mok T, et al. Gefitinib versus docetaxel in previously treated non-small-cell lung cancer (INTEREST): a randomised phase III trial. Lancet. 2008;372:1809-1818.

\section{Publish your work in this journal}

OncoTargets and Therapy is an international, peer-reviewed, open access journal focusing on the pathological basis of all cancers, potential targets for therapy and treatment protocols employed to improve the management of cancer patients. The journal also focuses on the impact of management programs and new therapeutic agents and protocols on

\section{Dovepress}

patient perspectives such as quality of life, adherence and satisfaction The manuscript management system is completely online and includes a very quick and fair peer-review system, which is all easy to use. Visit http://www.dovepress.com/testimonials.php to read real quotes from published authors.

Submit your manuscript here: http://www.dovepress.com/oncotargets-and-therapy-journal 